\title{
Kin recognition by phenotype matching in female Belding's ground squirrels
}

\author{
WARREN G. HOLMES \\ Psychology Department, University of Michigan, Ann Arbor, Michigan, 48109, U.S.A.
}

\begin{abstract}
Female Belding's ground squirrels (Spermophilus beldingi), that had been reared apart from each other, were observed in paired-encounter tests to determine whether exposure to nestmates' phenotypes during development had influenced their subsequent social discriminations. As a result of cross-fostering, test partners were (1) either unfamiliar sisters (reared apart) or unfamiliar, unrelated females, and were (2) either reared with each other's siblings (indirectly exposed to each other) or were not reared with each other's siblings (not indirectly exposed to each other). Regardless of relatedness, females that were indirectly exposed to each other were significantly less agonistic during tests than females not indirectly exposed to each other. This suggests that females learned something from their nestmates' phenotypes and later recalled what they had learned in order to distinguish between their nestmates' unfamiliar kin and non-kin. Furthermore, sisters that were indirectly exposed to each other were less agonistic than nonsisters that were indirectly exposed to each other. This was true even when the only kin phenotypes females had experienced during rearing were their own, which suggests that females may have compared unfamiliar phenotypes with their own, as well as those of their nestmates. Thus, the phenotypes that females encountered during rearing, both their nestmates' and their own, influenced their later social discriminations, probably by phenotype matching. Under this recognition mechanism, an individual forms a hypothetical 'kin template' based on its own or its familiar relatives' phenotypes, and later compares the phenotypes of other conspecifics with the learned template.
\end{abstract}

\section{INTRODUCTION}

The social stimuli experienced by developing young are often important in establishing their later behaviour toward those stimuli. For example, odours experienced by unweaned mammals can dictate subsequent olfactory preferences (Alberts 1976). In many cases, adult mate choices depend on the conspecifics they were exposed to during rearing (Dewsbury 1982; Bateson 1983). Imprinting (Lorenz 1935) and results from inter-specific crossfostering experiments (Porter et al. 1977; Huck \& Banks 1980) also affirm the role of early exposure on later social preferences.

Kin selection theory (Hamilton 1964; West Eberhard 1975) predicts that genetic relatedness is one factor that will influence social interactions (reviews in Kurland 1980; Alexander \& Tinkle 1981). Although kin selection does not require the evolution of specialized recognition abilities, or that animals be able to assess genetic relatedness directly, Hamilton (1964) outlined several proximal mechanisms to facilitate kin-differential behaviour and proposed that 'the situations which a species discriminates in its social behaviour tend to evolve and multiply in such a way that the coeffi- cients of relationship involved in each situation become more nearly determinate.' (page 24). More recently, the discrimination of kin has been discussed with regard to mate choice and a balance between inbreeding and outbreeding (Shields 1982; Bateson 1983).

Early association with conspecifics (e.g. nestmates or care-givers) provides one proximate link for the identification and preferential treatment of relatives, as predicted by kin selection theory (Bekoff 1981; Holmes \& Sherman 1983). In experimental tests, for instance, individuals reared together, regardless of true relatedness, are often tolerant of each other and intolerant of their related 'non-rearingmates' (Porter et al. 1981; Carlin \& Hölldobler 1983; Holmes 1984a). In these cases, relatives are not identified as kin per se, but rather as individuals experienced under some particular circumstances during development (Poindron \& Le Neindre 1980; Beecher et al. 1981; Holmes 1984b).

There is a second general process called 'comparing phenotypes' (Alexander 1979) or 'phenotype matching' (Holmes \& Sherman 1982) by which early exposure can mediate kin-directed behaviour. In phenotype matching, an individual learns the 
attributes of its own phenotype, or those of its relatives (e.g. nestmates or care-givers), in a certain context. This learning results in the formation of a hypothetical kin template or model, based on some phenotypic trait or suite of traits. When the individual later encounters a conspecific of unknown relatedness, it matches the unknown phenotype against the learned template. The assessment of relatedness is thus based on the degree of fit (quantitative or qualitative) between the unknown phenotype and the learned template, in a manner that may parallel stimulus generalization (Schwartz 1984).

Like any recognition mechanism, phenotype matching does not yield precise, error-free information about coefficients of relationship. In fact, the validity and reliability of phenotype matching may vary widely, depending on a host of factors (Lacy \& Sherman 1983). Thus phenotype matching may indicate the probability that individuals are related, and it may more reliably distinguish categories of conspecifics (e.g. close kin versus non-kin, half-siblings versus cousins) than individuals (Alexander 1979). In theory, however, there are circumstances under which more precise information about coefficients of relationship (e.g. Barash et al. 1978), or particular loci in the genome (e.g. Lenington 1983; Yamazaki et al. 1983), might be advantageous, and phenotype matching is one process that could facilitate such discriminations.

A correlation between phenotypic features and the genotype is critical to phenotype matching so that detectable traits are more similar among relatives than non-relatives (Holmes \& Sherman 1982). This correlation could result from the expression of shared genes (Greenberg 1979; Hölldobler \& Michener 1980), from the acquisition of a unique label from an environmental source to which only kin-group members are exposed (Pfennig et al. 1983), or from a combination of both. The source of the correlation. however, is not critical to the matching process as long as phenotypic and genotypic similarity co-vary more among kin than non-kin. For kin-correlated resemblance based on genetic factors, models have been used to examine how the accuracy of assessing relatedness depends on the number of independently assorting traits perceivable, their heritability and variation in the population, and the algorithm used to assess kinship based on phenotypic traits (Getz 1981, 1982; Beecher 1982; Lacy \& Sherman 1983).

Kin templates might be acquired when an indi- vidual learns the phenotypes of its nestmates, caregivers, or other relatives by associating with them. In a study on sibling recognition in spiny mice (Acomys cahirinus), for example, Porter et al. (1983) suggest that the phenotypes of litter-mates $\therefore$. can influence interactions among $A$. cahirinus weanlings by serving as a learned standard against which odours of conspecifics are compared.' (pp. 982-983). When kin labels are environmentally acquired, a template could be formed based on an encounter with the environmental source that imparts the label, rather than on direct encounters with relatives (Pfennig et al. 1983).

An individual's own phenotype could also serve as a recognition template, either directly by selfinspection or indirectly by inspection of a part of the environment that was labelled by the individual. In either case, when traits used in template formation are genetically, rather than environmentally, derived, self-matching may be advantageous because an individual's own phenotype would typically provide a more accurate kin referent than one based on the phenotypes of associates which could be compromised by multiple mating (Hanken \& Sherman 1981; Getz \& Smith 1983), cuckoldry (Daly \& Wilson 1982), communal rearing (Emlen 1984), or the early association and mixing of non-kin (O'Hara \& Blaustein 1982; Waldman 1984). Although self-matching has not been reported, individuals that identify their relatives despite being reared only among non-kin (Wu et al. 1980; but see Fredrickson \& Sackett 1984), among unequally related kin (Getz \& Smith 1983), or in social isolation (Blaustein \& O'Hara 1981, 1982, Waldman 1981) may be employing self-matching (Sherman \& Holmes 1985; but see Blaustein 1983).

I attempted to determine if phenotype matching could explain the ability of female Belding's ground squirrels (Spermophilus beldingi) to identify their sisters when reared apart from them. Holmes \& Sherman (1982) cross-fostered ( $<3 \mathrm{~h}$ post-partum) $S$. beldingi litter-mates to examine how genetic relatedness (siblings or non-siblings) and rearing association (reared together or reared apart) affected sibling recognition in the laboratory. As yearlings, siblings reared apart were significantly less agonistic during paired-encounter tests than non-siblings reared apart. More precisely, unfamiliar sister-sister pairs were less agonistic than were unrelated female-female pairs. whereas relatedness did not influence the interactions of unfamiliar male-male or unfamiliar male 
female pairs. Holmes \& Sherman (1982) proposed (page 505) that unfamiliar sisters might have '... learned something about the phenotypes of their sibling or nonsibling nestmates during rearing.... and then used this information to identify sisters with whom they were not reared .... To examine this further, I cross-fostered female $S$. belding $i$ and reared them with different numbers of related and unrelated young to determine if nestmates phenotypes influenced later social interactions between unfamiliar females. Given the importance of kinship to the social behaviour of female Belding's ground squirrels (Sherman 1977, 1980, 1981), their social discrimination abilities warrant study.

\section{METHODS}

\section{Rearing, Cross-fostering, and Test Groups}

Ground squirrels were born in captivity to pregnant females $(N=71)$ that were live-trapped near Tioga Pass, Mono County (1979, 1980, 1981) or Kirkwood, Placer County (1982), in the eastern Sierra Nevada of California. Each dam was housed individually in a stainless steel cage $(61 \times 45 \times 35$ $\mathrm{cm})$ that held a plywood nestbox $(25 \times 15 \times 12 \mathrm{~cm})$ filled with woodshavings. Water and food (Purina mouse breeder chow) were typically available ad libitum and lettuce and sunflower seeds were supplied occasionally each week. Cages remained in an indoor room (circa $6 \mathrm{~m}^{2}, 20 \pm 2 \mathrm{C}, 14: 10 \mathrm{~L}: \mathrm{D}$ cycle; $1979,1980,1982$ ) or an outdoor enclosure (circa $9 \mathrm{~m}^{2}$, ambient temperature and natural photoperiod in Berkeley, California; 1981) throughout the development of juveniles. Nestboxes were inspected for newborns three to six times per day. Within a few $(<12)$ hours of birth (late June or early July), pups were weighed, sexed, and toe-clipped (permanent identification) and then returned to their dam to await cross-fostering (below).

Test pairs were created by cross-fostering pups within sets of four dams that bore litters within $72 \mathrm{~h}$ of each other. Each test pair was composed of two females (sisters or unrelated females) that were reared apart from each other (unfamiliar females). More specifically, infants produced by two dams, A and $B$, were switched between these dams, and infants produced by the other two dams, C and D, were switched between these dams, if all four delivered within a 72-h period (Fig. 1). Both sexes were cross-fostered and the number of pups
DESIGN OF EXPERIMENT

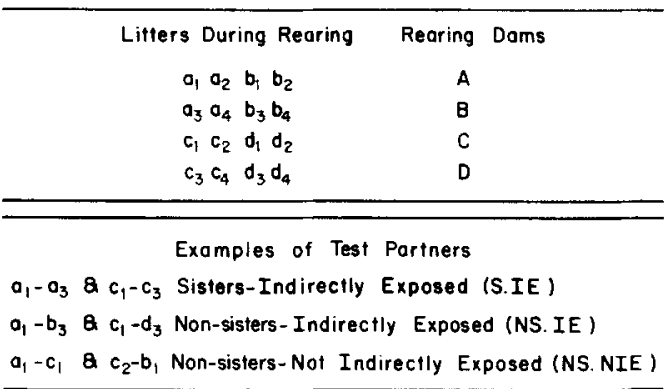

Figure 1. An example of litter composition during rearing created by cross-fostering newborn ( $<72$-h-old) Belding's ground squirrels. Young represented by a common letter are siblings. Also shown are examples of female female test partners from three experimental groups whose agonistic interactions were recorded during paired encounters. 'Indirectly exposed' indicates that females reared apart from each other were each reared with their test partner's siblings. The diagram shows only one of several examples of litter size and composition (number of related and unrelated nestmates) used in the investigation.

exchanged between dams varied as a function of litter size, sex ratio, and experimental groups (below).

During rearing a female was exposed to two categories of juvenile phenotypes based on kinship: relatives (her own and her siblings) and nonrelatives (her unrelated nestmates). Because pups were not exchanged between dams that were trapped less than $400 \mathrm{~m}$ from each other, it was unlikely that these foster mothers were inseminated by the same male or that they were close relatives (see Sherman 1981). Because multiple mating regularly results in multiple paternity in Belding's ground squirrel litters, 'sibling' actually refers to litter-mate siblings, which could be full- or maternal half-siblings (Hanken \& Sherman 1981).

Following cross-fostering, test pairs were categorized according to genetic relatedness and rearing exposure. 'Relatedness' indicated whether a pair was composed of sisters (S) or non-sisters (NS). 'Rearing exposure' indicated whether test partners were reared with each other's siblings, but not whether they were reared together (only unfamiliar females were tested). If partners were reared with each others' siblings, they were indirectly exposed (IE) to each other; if partners were not reared with each other's siblings, they were not indirectly exposed (NIE) to each other. Pairs were tested from three groups (Fig. 1): sisters indirectly 
exposed to each other (S.IE); non-sisters indirectly exposed to each other (NS.IE), and: non-sisters not indirectly exposed to each other (NS.NIE). Sisters not indirectly exposed to each other could not be tested because a female was always exposed to her own phenotype, one to which her sister was related.

Pairs were further categorized according to the 'kin:non-kin number', which is the number of related phenotypes (including her own) and nonrelated phenotypes, respectively, that a female was exposed to during rearing. Females in a given test pair (test partners) experienced the same kin: nonkin number during rearing. For example, if dam $A$ produced four young $\left(a_{1}, a_{2}, a_{3}\right.$, and $\left.a_{4}\right)$ and dam $B$ produced five young $\left(b_{1}, b_{2}, b_{3}, b_{4}\right.$, and $\left.b_{5}\right)$, within the 72-h time limit, one of dam B's young (e.g. $b_{5}$ ) was removed completely and two were reciprocally exchanged between $A$ and $B$. Thus, dam $A$ reared $a_{1}, a_{2}, b_{1}$, and $b_{2}$, while dam $B$ reared $b_{3}, b_{4}, a_{3}$, and $\mathrm{a}_{4}$ so that, for both litters, sizes and kin:non-kin numbers were identical (Fig. 1). Females were exposed to one of six kin:non-kin numbers: $1: 1,1$ : $3,3: 1,2: 3,3: 3$, or $3: 2$. Due to other constraints (i.e. the number of females producing litters, the timing of parturition, sex ratios at birth), it was not possible to control the sex ratios in litters during rearing. Note that a female experiencing a $1: 1$ or 1 : 3 number was exposed to only her own phenotype in the kin category and that the kin:non-kin number does not include the rearing dam's phenotype (see Discussion).

Within each of the three groups, at least nine pairs were reared under each of the six kin: non-kin numbers. Within a group, all pairs were 'unique', meaning that an individual female was a member of only one pair. However, each female was tested as a member of one pair in all three groups (e.g. $a_{1}$ and $c_{1}$ in Fig. 1).

Rearing-mates lived together until late August when each was housed individually $(25 \times 18 \times 16$ $\mathrm{cm}$ cage). In mid to late September, juveniles were moved to a coldroom to hibernate alone. About 7 months later, they were removed from the coldroom as yearlings and left in their individual cages with ad libitum access to food and water. Recognition tests began about 1 week later (circa 275 days of age).

\section{Recognition Tests}

I recorded the frequency of agonistic interactions during paired-encounter tests in a laboratory arena to assess sibling recognition following Holmes \& Sherman (1982). Tests were conducted in a $1-\mathrm{m}^{3}$ plywood arena (painted dull yellow) with a transparent Plexiglas front and an opaque dividing partition. An assistant first placed one dye-marked (for observer discrimination) female on each side of the arena's dividing partition. Then, if both females touched all four sides of their half of the arena within $5 \mathrm{~min}$, I lifted the divider with a rope and pulley from behind a screen where I was concealed during tests. A pair's social interactions were then described into a tape recorder during a 5-min test. Later, interactions were categorized as agonistic, exploratory, or neutral, based on previous descriptions (Steiner 1970; Sheppard \& Yoshida 1971; Michener \& Sheppard 1972). To be included in analyses, a pair had to interact at least five times during the 5-min test period. Females were returned to their individual cages after a test, and the arena was vacuumed and wiped with a dilute vinegar solution.

Females exhibited 11 types of agonistic encounters (definitions in Holmes \& Sherman 1982, Appendix I). Because it was not possible to weigh the intensity of one type (e.g. paw swipe) against another (e.g. fight) on the basis of biological criteria, the total number of agonistic encounters per pair was used to assess recognition. The mean number of agonistic encounters was calculated for each of the three groups and for each kin: non-kin number within a group. Of the 11 types of agonism, five (lateral arching, paw swipe, withdraw, 'threat' vocalizaton, and lunge strike) accounted for $76.1 \%$ of all encounters, based on the combined data from all groups. Each of these five types occurred regularly in all groups so that if, for each of the three groups, one separately examined the five most common agonistic encounters, the same ranking emerged among the groups (least to most agonistic) as when the five types were combined into a single score. Therefore, a combined score based on all 11 encounter types was used to represent a pair's behaviour. Only agonistic behaviours were analysed because they are more reliably categorized than exploratory or neutral behaviours (Holmes, unpublished data), and they occur frequently and can be correlated with categories of close and distant kin in the field (Sherman 1981). Females were tested as yearlings because juveniles are rarely agonistic during laboratory tests (Holmes \& Sherman 1982) and because the behaviour of free-living females that are one year of age 
or older is influenced by kinship (Sherman 1981).

Before the first tests began (March 1980), videotapes were made of the arena behaviour of 11 pairs and were scored for agonistic encounters. Interobserver $(N=2)$ agreement on the total number of agonistic encounters per pair was high $(r=0.88$, $P<0.05)$. To increase consistency in scoring between years, I re-scored the original videotapes each year before testing new pairs. During the 14 20-day period when ground squirrels were tested each spring, I observed a total of 145-170 pairs divided among three studies. Animals were marked with dots to distinguish test partners, but several (circa 10) shared similar marks. Assistants determined pair test orders randomly, and I was not aware of a pair's identity (the study or group within a study) during observations. During the first spring that data were collected (March 1980), pairs were observed three times at 5-day intervals for 15 min periods each day. Pair behaviour was stable over the three tests and the proportion of encounters that were agonistic did not differ between 5-min and 15-min tests (Holmes \& Sherman 1982). Accordingly, one 5-min test was used to quantify arena behaviour in 1980 and all subsequent years (1981-1983).

About 50 pairs were tested in each of the 4 years of the study, with 12-20 pairs per group. Based on a random sample of 10 pairs per group, per year, there were no significant $(P>0 \cdot 1)$ differences across the 4 years of data collection in the groups' mean frequencies of agonistic encounters. Therefore data from all years were combined for analyses. The behaviour of females tested in 1980 have been reported previously (Holmes \& Sherman 1982).

The mean $( \pm \mathrm{SE})$ number of agonistic encounters per pair is reported. Since data met the requirements for parametric statistics, means were compared with $t$-tests or one-way analyses of variance (ANOVA). Scheffe's test was used for the between-group comparisons of means following ANOVAs.

\section{RESULTS}

Data from 195 of 213 tested pairs $(91.5 \%)$ were analysed because females did not always move about the arena before the partition was lifted $(N=7$ pairs) and some pairs $(N=11)$ did not interact five times as required. About equal numbers of these 18 pairs came from each of the three groups. Females averaged $277 \cdot 3 \pm 5 \cdot 6$ days of age and $189 \cdot 8 \pm 11.3 \mathrm{~g}$ body weight at testing, and neither of these variables differed significantly $(P>0 \cdot 1)$ across the three groups.

\section{Relatedness and Rearing Exposure}

Females indirectly exposed to each other (sister and non-sister pairs combined) were significantly $(P<0.001)$ less agonistic during arena tests ( $\bar{X}=5 \cdot 2 \pm 0 \cdot 5, N=130$ pairs) than females that were not indirectly exposed to each other ( $\bar{X}=9 \cdot 0 \pm 0 \cdot 7, N=65$ pairs). When relatedness and rearing exposure were both considered (Fig. 2).

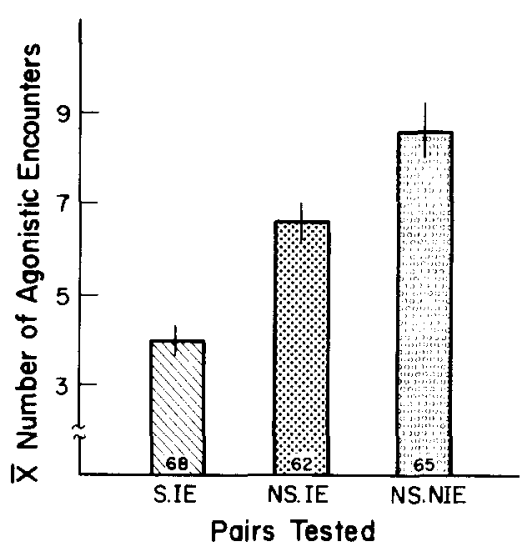

Figure. 2. The mean $( \pm S E)$ number of agonistic encounters recorded during 5 -min paired-encounter tests of female ground squirrels. Numbers of pairs tested are shown inside bars. The three groups are defined in the text and shown in Fig. 1.

sisters that were indirectly exposed to each other (S.IE) were significantly $(P<0.001)$ less agonistic than non-sisters that were indirectly exposed to each other (NS.IE). These, in turn, were significantly $(P<0.001)$ less agonistic than non-sisters that were not indirectly exposed to each other (NS.NIE). Thus, both relatedness and rearing exposure influenced female agonistic interactions.

There were also significant $(P<0.01)$ differences among the three groups in the total number of all encounter types combined (agonistic + exploratory + neutral), but the differences in agonism among groups (Fig. 2) were not due simply to differences in total social activity. The proportion of all encounters that were agonistic gave the same significant $(P<0.001)$ between-group differences $(\mathrm{S} . \mathrm{IE}<\mathrm{NS}$.IE $<$ NS.NIE). 


\section{Kin: Non-kin Rearing Number}

Agonism for each group (Fig. 2) was analysed on the basis of combined scores for all six kin : non-kin numbers, but data from each kin: non-kin number were also examined separately (Fig, 3). For each number, S.IE females were significantly $(P<0 \cdot 05)$ less aggressive than NS.IE females. Similarly, NS.IE females were always less agonistic than NS.NIE females, regardless of the pairs' kin:nonkin numbers. These differences were significant $(P<0.05)$ for numbers $1: 3,3: 3$, and $3: 2$ and approached significance $(P<0 \cdot 1)$ for numbers $1: 1$, $3: 1$, and $2: 3$. To summarize, for each of the six kin: non-kin numbers, the mean frequencies of agonistic encounters were ordered S.IE <NS.IE $<$ NS.NIE, and most of these between-group differences were significant for each kin:non-kin number (Fig. 3).

Within test groups, kin;non-kin numbers did not affect pairs" agonism (Fig. 3). One-way ANOVAs comparing means across the six kin:non-kin numbers were not significantly different $(P>0 \cdot 1)$ for the S.IE, the NS.IE, or the NS.NIE groups. Finally, for sister--sister pairs, I calculated the mean frequency of agonism for females exposed during rearing to only their own phenotype in the related category (numbers $1: 1$ and $1: 3$ ) and a mean for females exposed to at least one other relative's phenotype, besides their own (numbers $3: 1,2: 3$,

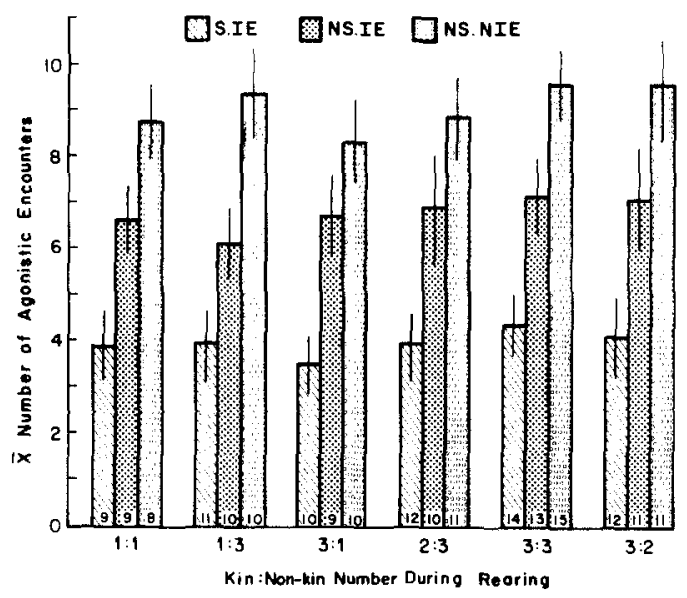

Figure 3. The mean ( $\pm \mathrm{SE}$ ) number of agonistic encounters recorded during dyadic tests of female ground squirrels reared with different numbers of sibling and non-sibling nestmates (the kin:non-kin number). Female-female pairs were tested from three groups (see text and Fig. 1) as indicated. Numbers of pairs tested are shown inside bars.
$3: 3$, and $3: 2$ ). These means did not differ significantly (own phenotype: $\bar{X}=3.8 \pm 0.8, N=20$; other relative's phenotype: $\bar{X}=4 \cdot 0 \pm 0 \cdot 7, N=48, P>0 \cdot 1$ ).

\section{DISCUSSION}

Female Belding's ground squirrels distinguished their unfamiliar sisters from unfamiliar unrelated females during paired-encounter tests and phenotype matching seems to explain this discrimination. When unfamiliar females were reared with their future test partner's kin (i.e. pair members were indirectly exposed to each other), they were less agonistic than unfamiliar females that were not indirectly exposed to each other, regardless of genetic relatedness (Fig. 2). However, sisters indirectly exposed to each other were even less agonistic than unrelated females indirectly exposed to each other. Furthermore, neither the total number of related or unrelated nestmates, nor the proportion of related to unrelated nestmates, influenced female-female agonism if test partners were indirectly exposed to each other (Fig. 3). Unfortunately, I could not determine whether the sex ratios in litters during rearing influenced agonistic encounters since I could not control sex ratios when young were cross-fostered (see Methods).

Differential treatment of nestmates' kin and nonkin demonstrates discrimination of these two categories, although it does not reveal whether individuals within each category are discriminable. $S$. beldingi females learn the phenotypes of both sibling and non-sibling young that they are reared with (Holmes \& Sherman 1982, Fig. 4), and the present study suggests that they may use what they learn to identify their own sisters and those of their unrelated nestmates.

Discrimination by females may also have been affected by the phenotypes of their rearing dams (e.g. Porter et al. 1981), but I could not examine this possibility. In paired-encounter tests with $S$. beldingi, agonism by one animal often elicits agonism from the other (Holmes, unpublished data). Because test partners were exchanged between two dams whose phenotypes were presumably dissimilar because they were unrelated, partners may have acquired quite different information from their dams' phenotypes. Since both partners could initiate and respond to each other during tests, I could not separate one female's discriminatory abilities from the other's and thus could not 
consider the influence of dams' phenotypes on arena interactions.

In an earlier study, Holmes \& Sherman (1982) suggested that unfamiliar sisters might have identified each other by phenotype matching (see Introduction), but it was not possible to determine whether (1) in-utero association, (2) early $(<3-\mathrm{h})$ post-natal association prior to cross-fostering, or (3) 'recognition alleles' (Hamilton 1964; Dawkins 1976) might explain the arena behaviour of unfamiliar females. None of these three possibilities explains the reduced agonism between NS.IE females compared with NS.NIE females (Fig. 2) because test partners did not associate pre- or postnatally, nor did they share alleles that were identical by descent. What did distinguish NS.IE from NS.NIE females was that they were reared with their test partner's kin and exposed to phenotypes that seemed to allow the identification of unfamiliar females by a matching process.

Phenotype matching has been verified in two species of insects. Buckle \& Greenberg (1981) created laboratory colonies of female sweat bees (Lasioglossum zephyrum) containing sisters and non-sisters and later placed unfamiliar intruders at the entrances of residents' colonies. Residents admitted unfamiliar intruders only if residents were reared with the intruders' siblings, regardless of resident-intruder relatedness. Thus, when confronted with unfamiliar conspecifics, both $L$. zephyrum and $S$. beldingi females respond, in part, according to whether they were reared with the stranger's close kin. On the other hand, $L$. zephyrum females do not appear to use their own phenotype in the matching process (Buckle \& Greenberg 1981), whereas $S$. beldingi females do seem to use their own phenotype (Holmes \& Sherman 1982 and below). In sweat bees, kin are identified largely by odours (Bell 1974; Barrows et al. 1975) that may arise primarily from a genetic source (Bell 1974) and are more similar among related than unrelated females (Kukuk et al. 1977; Greenberg 1979). Odours are also important to social discrimination in $S$. beldingi (Holmes 1984b). but the origin of the odours, their role (if any) in sibling-sibling recognition, and their similarity among relatives, are unknown.

In captive female paper wasps (Polistes fuscatus), environmentally-acquired traits (probably odours) seem partially responsible for phenotype matching. Pfennig et al. (1983) removed gynes (potential queens) as they emerged from their natal nest and transferred them to various experimental nests. Gynes individually exposed to separate fragments of the same experimental nests were more socially tolerant of each other than gynes individually exposed to separate fragments of different experimental nests, regardless of female-female relatedness or the identity of the original queens that constructed the experimental nests. Pfennig et al. (1983) suggest that $P$. fuscatus gynes acquire and learn odour cues from their natal nest and/or its contents and that 'by comparing the memory of cues learned from the nest and/or brood with cues of nestmates, a female can discriminate nestmates from non-nestmates' (page 304).

Neither Buckle \& Greenberg (1981) nor Pfennig et al. (1983) suggest that sweat bees or paper wasps, respectively, use phenotype matching to identify nestmates in nature. Indeed, the significance of phenotype matching to sister recognition in these species is unknown, although there may be field situations in which phenotype matching could be adaptive as, for example, during nest usurpations when females first encounter nests (brood-filled combs) built by non-kin (Klahn \& Gamboa 1983). In kin-recognition experiments (e.g. Davis 1982; Kareem 1983; Quinn \& Busack 1985), the purpose of manipulating such variables as the amount, location, or timing of exposure between kin is not necessarily to recreate the species-typical environment in which sibling recognition develops. Rather, the purpose is to identify proximal rules and sensory systems that might produce adaptive behaviour under species-typical conditions and to specify the factors that are critical to the development of these proximal rules.

Two things are suggested by the reduced agonism of S.IE pairs compared with NS.IE pairs. regardless of the number of kin or non-kin nestmates female $S$. beldingi were reared with (Fig. 3). First, indirect exposure alone does not explain this between-group difference because all females were indirectly exposed to their test partners, yet sisters were less aggressive than non-sisters for all kin: non-kin numbers. In contrast to sweat bees (Buckle \& Greenberg 1981) and paper wasps (Pfenning et al. 1983), which seem to respond only to indirect exposure, in $S$. beldingi, factors correlated with kinship also influence interactions between unfamiliar females reared with each others' relatives. Among these potential factors are pre- and postnatal $(<72-\mathrm{h})$ association and genes which are identical by descent. 
Second, the lack of differences in agonism as a function of kin:non-kin numbers implies something about the hypothetical template used in the matching process. When the only juvenile phenotypes available to females as kin referents were their own, (1) females were less aggressive with their unfamiliar sisters than with their nestmates' unfamiliar sisters and (2) they were no more aggressive than their unfamiliar sisters that were reared with their siblings (Fig. 3). These results are expected if females rely primarily on their own phenotype as a standard against which unfamiliar phenotypes are compared. In this regard, $S$. beldingi may differ from $L$. zephyrum because female sweat bees appear not to use their own phenotype to identify nestmates (Buckle \& Greenberg 1981; also see Holmes \& Sherman 1982 on Arctic ground squirrels, $S$. parryii). Furthermore, self-matching suggests a behavioural rule that would explain the contrast between agonism in S.IE and NS.NIE females: if an unfamiliar phenotype matched a female's own phenotype, she reduced her aggressive behaviour markedly (S.IE pairs), whereas if an unfamiliar phenotype matched only a nestmate's phenotype, the female was slightly less aggressive.

Although the data (Fig. 3) are consistent with the self-matching hypothesis, other explanations are possible. For example, Blaustein (1983) emphasizes that discrimination of unfamiliar kin could be mediated by self-matching or by 'recognition alleles' and that it would be difficult to distinguish these two mechanisms experimentally. (Actually this is true only if the genotype-phenotype correlation underlying phenotype matching is based on the phenotypic expression of genes shared in common, which does not have to be the case; see Introduction.) Whether the existence of 'recognition alleles' is questionable on the basis of parsimony or theoretical arguments (discussion in Dawkins 1982), it is difficult to examine rigorously the likelihood of their existence in the apparent absence of a formal and generally-accepted model of how they would act. For instance, Blaustein (1983) suggests that there may be no essential difference between self-matching and 'recognition alleles', whereas Dawkins (1982) views them as being very different.

Initially the ability of captive $S$. belding $i$ females to identify their unfamiliar sisters may seem paradoxical because, in nature, litter-mate sisters occupy a common natal burrow and this direct association represents the proximate basis for later recognition and cooperation (Sherman 1980: Holmes \& Sherman 1982; see also Holmes 1984a on $S$. tridecemlineatus). On the other hand, the rearing conditions I created may have revealed a general phenomenon (learning phenotypes encountered during rearing) that is characteristic of all female $S$. beldingi, but one that is detected only when direct association fails to distinguish conspecifics. For instance, relatives might not be recognizable based on direct association because (1) they do not share a common rearing environment (paternal halfsiblings) or (2) they share one with at least two categories of unequally related kin (maternal fulland half-siblings). Both of these situations may apply to Belding's ground squirrels. First, due to male polygyny (Hanken \& Sherman 1981) and female dispersal and survival (Sherman \& Morton 1984), paternal half-sisters may coexist. Phenotype matching against nestmates' or a female's own phenotype is one means by which paternal halfsiblings could be distinguished from non-kin.

Second, full- and maternal half-sisters that result from multiple mating by females (Hanken \& Sherman 1981) share a common uterine and natalburrow environment. Nevertheless, the preliminary data gathered on such females reveal that they treat their full-sisters preferentially over their halfsisters (Holmes \& Sherman 1982, Figs 9 and 10). The laboratory results (Fig. 3) for females exposed to only their own phenotype in the kin category suggest that full- and half-sister discrimination could occur by self-matching. Holmes \& Sherman (1982) reasoned that self-matching was also implicated by a field experiment in which unweaned young were inserted into occupied natal burrows (aliens and burrow residents were unrelated). As yearlings, aliens were treated more like maternal half-sisters than full-sisters (Holmes \& Sherman 1982). According to the investigators, this outcome was expected if $S$. beldingi females used selfmatching to distinguish two categories of conspecifics with dichotomous classes in each: first, females either shared ego's natal burrow with her (ego 's litter-mates) or they did not (ego's non-littermates); second, females were either phenotypically similar to ego (her full-sisters) or they were not (her maternal half-sisters and her foster litter-mates).

In conclusion, phenotype matching seems to explain the ability of female Belding's ground squirrels to identify unfamiliar females in laboratory tests. Females appeared to learn phenotypes they encountered during rearing and later used 
what they had learned to identify unfamiliar females. When an unfamiliar female's phenotype matched the phenotype of ego's nestmates, aggression was reduced compared with what happened when no match occurred (S.IE pairs or NS.IE pairs versus NS.NIE pairs in Fig. 2). Moreover, when an unfamiliar female's phenotype matched ego's own phenotype (i.e. self-matching), aggression was reduced even further (S.IE pairs versus NS.IE pairs for kin: non-kin numbers $1: 1$ and $1: 3$ in Fig. 3). Phenotype matching is based on learning and represents a proximal mechanism used to distinguish relatives when direct association does not provide a reliable cue for kin-differentiated behaviour.

\section{ACKNOWLEDGMENTS}

I thank D. Bushberg, D. DiMario, D. Gelfand, B. Grimm, C. Rowley, and L. Shellberg for laboratory assistance with the ground squirrels; R. Caldwell, S. Glickman, M. Redfearn, and I. Zucker for equipment and help in acquiring, caring for, and shipping animals; M. Coffey and R. Kushler for statistical advice; and M. Beecher, L. Blumer, J. Galef, G. Gamboa, S. Lenington and P. Sherman for their valuable comments on drafts of this paper. My thinking about kin recognition and phenotype matching was stimulated by conversations with $\mathbf{R}$. Alexander, W. Hamilton, and P. Sherman, who also shared with me his extensive knowledge about Belding's ground squirrels. This research was supported with funds from the Office of the Dean of the College of Literature, Science, and the Arts, the Office of the Vice President for Research, a Rackham Faculty Research Grant, and the Department of Psychology, all from the University of Michigan.

\section{REFERENCES}

Alberts, J. R. 1976. Olfactory contributions of behavioral development in rodents. In: Mammalian OlfactionReproductive Processes and Behavior (Ed. by R. L. Doty), pp. 67-94. New York: Academic Press.

Alexander, R. D. 1979. Darwinism and Human Affairs. Seattle: University of Washington Press.

Alexander, R. D. \& Tinkle, D. W. 1981. Natural Selection and Social Behavior: Recent Research and New Theory. New York: Chiron Press.

Barash, D. P., Holmes, W. G. \& Greene, P. J. 1978. Exact versus probabilistic coefficients of relationships: some implications for sociobiology. Am. Nat., 112, 355-363.
Barrows, E. M., Bell, W. J. \& Michener, C. D. 1975. Individual odor differences and their social functions in insects. Proc. Natl Acad. Sci. U.S.A., 72, 2824-2828.

Bateson, P. P. G. 1983. Optimal outbreeding. In: Mate Choice (Ed. by P. P. G. Bateson), pp. 257-277. Cambridge: Cambridge University Press.

Beecher, M. D. 1982. Signature systems and kin recognition. Am. Zool, 22, 475-490.

Beecher, M. D., Beecher, I. M. \& Nichols, S. H. 1981. Parent-offspring recognition in bank swallows (Riparia riparia): II. Development and acoustic basis. Anim. Behav., 29, 95-101.

Bekoff, M. 1981. Mammalian sibling interactions: genes, facilitative environments, and the coefficient of familiarity. In: Parental Care in Mammals (Ed. by D. J. Gubernick \& P. H. Klopfer), pp. 307--346. New York: Plenum Press.

Bell, W. J. 1974. Recognition of resident and non-resident individuals in intraspecific nest defense of a primitively eusocial halictine bee. J. comp. Physiol., 93, 195-202.

Blaustein, A. R. 1983. Kin recognition mechanisms: phenotypic matching or recognition alleles? Am. Nat., 121, 749-754.

Blaustein, A. R. \& O'Hara, R. K. 1981. Genetic control for sibling recognition. Nature, Lond., 290, 246-248.

Blaustein, A. R. \& O'Hara, R. K. 1982. Kin recognition in Rana cascadae tadpoles: maternal and paternal effects. Anim. Behav., 30, 1151-1157.

Buckle, G. R. \& Greenberg, L. 1981. Nestmate recognition in sweat bees (Lasioglossum zephyrum): does an individual recognize its own odour or only odours of its nestmates? Anim. Behav., 29, 802-809.

Carlin, N. F. \& Hölldobler, B. 1983. Nestmate and kin recognition in interspecific mixed colonies of ants. Science, N.Y., 222, 1027-1029.

Daly, M. \& Wilson, M. I. 1982. Whom are newborn babies said to resemble? Ethol. Sociobiol., 3, 69-78.

Davis, L. S. 1982. Sibling recognition in Richardson's ground squirrels (Spermophilus richardsonii). Behat. Ecol. Sociobiol., 11, 65-70.

Dawkins, R. 1976. The Selfish Gene, New York and Oxford: Oxford University Press.

Dawkins, R. 1976. The Selfish Gene. New York and Oxford: Oxford University Press.

Dewsbury, D. A. 1982. Avoidance of incestuous breeding between siblings in two species of Peromyscus mice. Biol. Behav., 7, 157-169.

Emlen, S. T. 1984. Cooperative breeding in birds and mammals. In: Behavioural Ecology: An Evolutionary Approach. 2nd edn (Ed. by J. R. Krebs \& N. B. Davies), pp. 305-339. Sunderland: Sinauer Associates.

Fredrickson, W. T.\& Sackett, G. P. 1984. Kin preferences in primates (Macaca nemestrina): relatedness or familiarity. J. comp. Psychol., 98, 29-34.

Getz, W. M. 1981. Genetically based kin recognition systems. J. theor. Biol., 92, 209-226.

Getz, W. M. 1982. An analysis of learned kin recognition in Hymenoptera. J. theor. Biol., 99, 585-597.

Getz, W. M. \& Smith, K. B. 1983. Genetic kin recognition: honey bees discriminate between full and half sisters. Nature, Lond., 302, 362-365.

Greenberg, L. 1979. Genetic component of bee odor in kin recognition. Science, N.Y., 206, 1095 1097. 
Hamilton, W. D. 1964. The genetical evolution of social behaviour, I, II. J. theor. Biol, 7, 1-52.

Hanken, J. \& Sherman, P. W. 1981. Multiple paternity in Belding's ground squirrel litters. Science, N.Y., 212 , $351-353$.

Hölldobler, B. \& Michener, C. D. 1980. Mechanisms of identification and discrimination in social hymenoptera. In: Evolution of Social Behavior: Hypotheses and Empirical Tests (Ed. by H. Markl), pp. 35-58. Weinheim: Verlag Chemie.

Holmes, W. G. 1984a. Sibling recognition in thirteenlined ground squirrels: effects of genetic relatedness. rearing association, and olfaction. Behav. Ecol. Sociobiol., 14, 225-233.

Holmes, W. G. 1984b. Ontogeny of dam-young recognition in captive Belding's ground squirrels. J. comp. Psychol., 98, 246-256.

Holmes, W. G. \& Sherman, P. W. 1982. The ontogeny of kin recognition in two species of ground squirrels. $\mathrm{Am}$. Zool., 22, 491-517.

Holmes, W. G. \& Sherman, P. W. 1983. Kin recognition in animals. $A m$. Sci., 71, 46-55.

Huck. U. W. \& Banks, E. M. 1980. The effects of crossfostering on the behaviour of two species of North American lemmings, Dicrostonyx groenlandicus and Lemmus trimucronatus: I. Olfactory preferences. Anim. Behav., 28, 1046-1052.

Kareem, A. M. 1983. Effect of increasing periods of familiarity on social interactions between male sibling mice. Anim. Behat., 31, 919-926.

Klahn, J. E. \& Gamboa, G. J. 1983. Social wasps: discrimination between kin and nonkin brood. Science, N.Y., 221, 482484.

Kukuk, P. F.. Breed. M. D., Sobti, A. \& Bell, W. J. 1977. The contributions of kinship and conditioning to nest recognition and colony member recognition in a primitively eusocial bee, Lasioglossum zephyrum (Hymenoptera: Halictidae). Behav. Ecol. Sociobiol., 2, 319-327.

Kurland, J. A. 1980. Kin selection theory: a review and selective bibliography. Ethol. Sociobiol., 1, 255-274.

Lacy, R. C. \& Sherman, P. W. 1983. Kin recognition by phenotype matching. Am. Nat., 121, 489-512.

Lenington, S. 1983. Social preferences for partners carrying 'good genes' in wild house mice. Anim. Behat.. 31, 325-333.

Lorenz, K. 1935. Der Kumpan in der Umwelt des Vogels. J. Ornithol., 83, 137-213; 289-413.

Michener, G. R. \& Sheppard, D. H. 1972. Social behavior between adult Richardson's ground squirrels (Spermophilus richardsonii) and their own and alien young. $C a n$. J. Zool., 50, 1343-1349.

O'Hara, R. K. \& Blaustein, A. R. 1982. Kin preference behavior in Bufo boreas tadpoles. Behat. Ecol. Sociobiol., 11, 43-49.

Pfennig, D. W., Gamboa, G. J., Reeve, H. K., Shellman Reeve, J. \& Ferguson, I. D. 1983. The mechanism of nestmate discrimination in social wasps (Polistes. Hymenoptera: Vespidae). Behav. Ecol. Sociobiol., 13, 299-305.

Poindron, P. \& Le Neindre, P. 1980. Endocrine and sensory regulation of maternal behavior in the ewe Adr. Stud. Behat., 11, 75-119.

Porter, R. H., Deni, R. \& Doane, H. M. 1977. Responses of Acomys cahirinus pups to chemical cues produced by a foster species. Behat. Biol., 20, 244 251

Porter, R. H., Tepper, V. J. \& White, D. M. 1981. Experiential influences on the development of huddling preferences and 'sibling" recognition in spiny mice. Del Psychobiol., 14, 375-382.

Porter, R. H., Matochik, J. A. \& Makin, J. W. 1983. Evidence for phenotype matching in spiny mice (Acomys cahirinus). Anim. Behav., 31, 978 984.

Quinn, T. P. \& Busack, C. A. 1985. Chemosensory recognition of siblings in juvenile coho salmon (Oncorhynchus kisutch). Anim. Behav., 33, 5156.

Schwartz, B. 1984. Psychology of Learning and Behatior. 2nd edn. New York: W. W. Norton.

Sheppard, D. H. \& Yoshida, S. M. 1971. Social behavior in captive Richardson's ground squirrels. J. Mammal., 52, 793-799.

Sherman, P. W. 1977. Nepotism and the evolution of alarm calls. Science, N.Y., 197, 1246-1253.

Sherman, P. W. 1980. The limits of ground squirrel nepotism. In: Sociobiology: Beyond Nature Nurfure? (Ed. by G. W. Barlow \& J. Silverberg), pp. 505.544. Boulder, Colorado: Westview Press.

Sherman, P. W. 1981. Kinship, demography, and Belding's ground squirrel nepotism. Behat. Ecol. Sociobiol. 8, 251-259.

Sherman, P. W. \& Holmes, W. G. 1985. Kin recognition: issues and evidence. In: Experimental Behavioral Eco$\log y$ and Sociobiology (Ed. by B. Hölldobler \& $\mathbf{M}$. Lindauer), pp. 437-460. Stuttgart: Gustav Fischer Verlag.

Sherman, P. W. \& Morton, M. L. 1984. Demography of Belding's ground squirrels. Ecology, 65, 1617 1628.

Shields, W. M. 1982. Philopatry, Inbreeding, and the Evolution of Sex. Albany, N.Y.: State University of New York Press.

Steiner, A. L. 1970. Étude descriptive de quelques activités et comportement de base de Spermophihus columbianus columbianus (Ord). II. Vie de groupe. Rev. Comp. Anim., 4, 23-42.

Waldman, B. 1981. Sibling recognition in toad tadpoles: the role of experience. $Z$. Tierpsychol., 56, 341 358.

Waldman, B. 1984. Kin recognition and sibling association among wood frog (Rana syltatica) tadpoles. Behav. Ecol. Sociobiol., 14, 171-180.

West Eberhard, M. J. 1975. The evolution of social behavior by kin selection. $Q$. Ret. Biol., 50, 1-33.

Wu, H. M. H., Holmes, W. G., Medina, S. R. \& Sackett, G. P. 1980. Kin preference in infant Macaca nemestrina. Nature, Lond., 285, 225-227.

Yamazaki, K., Beauchamp, G. K., Wysocki, C. J., Bard, J., Thomas, L. \& Boyse, E. A. 1983. Recognition of H-2 types in relation to the blocking of pregnancy in mice. Science, $N . Y ., 221,186-188$.

(Received 11 July 1984; revised 23 Norember 1984; MS number: A4344) 